\title{
的 \\ EDUCAÇÃO LEGISLATIVA: \\ AS ESCOLAS DO LEGISLATIVO E A FUNÇÃO EDUCATIVA DO PARLAMENTO1
}

\author{
Alaôr Messias Marques Júnior ${ }^{2}$
}

Resumo: $\mathrm{O}$ adequado funcionamento da democracia exige determinadas capacidades e competências por parte dos agentes políticos e sociais. O texto trata das possibilidades e das responsabilidades da educação legislativa como instrumento para a construção dessas competências no âmbito do parlamento e do papel das escolas do legislativo nesse contexto.

Palavras-chave: Educação legislativa; Escola do Legislativo

Abstract: Democracy demands certain capacities and skills from the political and social agents. The article refers to the legislative education, as a tool for the construction of these capacities within the parliament, and to the role of legislative schools in this context.

Keywords: Legislative education; Legislative school

\section{Introdução}

Entre as condições essenciais ao funcionamento da democracia merecem destaque a sistemática de representação e/ou de participação da sociedade na arena governamental, bem como as formas e mecanismos de relacionamento entre representantes e representados. Tais questões têm sido objeto de preocupação permanente - não apenas por parte de estudiosos e especialistas, mas também das instituições e dos agentes políticos, como, de resto, da própria sociedade - especialmente em países como o Brasil, onde a experiência democrática ainda se encontra em processo de consolidação. O Poder Legislativo tem um papel e um interesse estratégicos nesse debate, tendo em vista, por um lado, a sua posição central no sistema

\footnotetext{
${ }^{1}$ Artigo baseado na monografia de conclusão do Curso de Especialização em Poder Legislativo, oferecido pela PUC Minas e pela Escola do Legislativo da Assembleia de Minas Gerais.

${ }^{2}$ Especialista em Poder Legislativo. Gerente-Geral da Escola do Legislativo da Assembleia Legislativa do Estado de Minas Gerais. Endereço eletrônico: alaor@almg.gov.br.
} 
democrático, bem como, por outro, os graves e constantes problemas por que passa a representação política nos dias atuais.

É nesse contexto que se inserem as discussões sobre a educação legislativa, enquanto uma ação consciente e organizada do parlamento no sentido de capacitar e qualificar a atuação dos diferentes agentes envolvidos no processo de representação e participação democrática, tanto da perspectiva das instituições estatais quanto da sociedade. Essa ação tem ganhado força e resultados nos últimos anos, seja pelo reconhecimento crescente do papel educativo do parlamento, a par das demais funções tradicionalmente consideradas, seja pela criação, consolidação e ampliação, no âmbito dessas casas, de órgãos e setores voltados para o exercício efetivo dessa missão pedagógica, aqui genericamente denominados como escolas do legislativo.

Propõe-se aqui, assim, reforçar e proporcionar fundamentação ao trabalho educativo desenvolvido pelos parlamentos, por intermédio das respectivas escolas do legislativo, localizando-o no contexto da teoria democrática, especialmente com relação a seus pressupostos de representação e participação política. Pretende-se ainda traçar os contornos da educação legislativa, seja em termos da sua relação com o exercício da função informadora do parlamento, seja em termos da delimitação do seu escopo em face da atuação educativa esperada também das demais instituições que compõem o aparato estatal.

\section{Democracia: representação, participação e deliberação}

O modelo de democracia adotado nas sociedades contemporâneas, em face da evidente impossibilidade, especialmente em contextos mais complexos, de uma permanente interação face-a-face entre todos os atores envolvidos nos processos de deliberação pública, pressupõe a implementação de uma sistemática de representação da vontade popular por agentes escolhidos pela própria sociedade.

A assim chamada democracia representativa depende, no entanto, de algumas condições essenciais para a sua adequada operação, especialmente em termos da dinâmica de interação entre a sociedade e seus representantes. A primeira dessas condições diz respeito à formulação e observância de regras - pré-estabelecidas, fixas e conhecidas, bem como informadas pelos princípios da igualdade política e da soberania popular - tanto para a escolha quanto para a atuação desses representantes. A segunda refere-se à existência e ao funcionamento de canais e mecanismos institucionalizados e permanentes que permitam aos representados expressar (e/ou aos representantes identificar), de forma continuada, as necessidades, vontades e interesses da sociedade. A terceira condição está relacionada à necessidade de que os representados, no sentido inverso, tenham acesso a recursos e informações que lhes permitam o exercício da accountability vertical, ou seja, o conhecimento, a fiscalização e o controle sobre os atos não apenas dos seus representantes eleitos, como também dos demais agentes públicos. A última (mas não menos importante) dessas condições concerne às capacidades requeridas, tanto por 
parte de representantes quanto de representados, para o adequado exercício de seus papéis e funções na arena democrática (Anastasia; Inácio, 2006).

Espera-se, com tudo isso, que essa representação, que tem no Poder Legislativo o seu locus principal, constitua um elo efetivo entre sociedade e Estado, no sentido de orientar a atuação deste em consonância com as expectativas daquela, bem como, especialmente, de permitir a transformação das demandas sociais em políticas públicas e estas, por sua vez, em resultados concretos para a coletividade. É óbvio, no entanto, que a dinâmica da representação e, por conseguinte, da própria democracia, tem se tornado tanto mais complexa quanto mais também se complexifica, ao longo do tempo, a realidade social e política. Nesse contexto, o modelo básico de representação - em que a participação e a manifestação de preferências dos cidadãos acontecem apenas no momento da eleição dos seus representantes, com a consequente delegação a estes da responsabilidade exclusiva de tomar decisões em nome da coletividade ao longo do mandato - tem se mostrado totalmente insuficiente para o atendimento aos requisitos da plena democracia. Tal modelo, se, por um lado, não permite a necessária identificação e/ou manifestação de interesses e demandas da sociedade entre os períodos eleitorais, por outro limita a esperada atuação, tanto dos representantes quanto dos próprios cidadãos, nos processos de deliberação pública.

Diante dessa crise da representação, observa-se, então, uma tentativa de revalorização da democracia participativa, especialmente por meio da crescente adoção de inovações institucionais, por parte dos diferentes poderes e esferas governamentais, no sentido da participação da sociedade no processo legislativo e decisório. Os ganhos resultantes da convivência entre o sistema de democracia representativa e tais instrumentos de democracia participativa têm sinalizado para a necessidade e as possibilidades de uma articulação cada vez maior entre representação e participação, vistas hoje, não como excludentes, mas como complementares.

É preciso ainda, no entanto, avançar no sentido de um modelo de democracia deliberativa, em que essas instâncias de representação e de participação se tornem espaços em que as decisões políticas resultem "[...]de um processo de formação e transformação das próprias preferências e dos interesses particulares, no sentido de se alcançarem acordos políticos que tenham a seu favor uma pretensão de racionalidade" (Werle; Melo, 2007).

Anastasia e Inácio (2006) propõem, então, uma articulação entre os modelos de representação, participação e deliberação. Para as autoras,

a deliberação, nas democracias contemporâneas, deve estar, necessariamente, em ambos os pólos - representação e participação - assim como nos canais através dos quais representação e participação se comunicam e interagem. Portanto, não apenas as Casas Legislativas devem ser instâncias deliberativas, como o que nelas se delibera deve ecoar e reverberar, da melhor forma possível, os processos de deliberação em curso nas entidades de participação política da sociedade civil. Para tanto, requer-se que haja canais permanentes, institucionalizados e deliberativos de interação entre as 
instâncias de representação e de participação política (Anastasia e Inácio, 2006, grifo das autoras).

\section{Informação e Educação para o Exercício Democrático}

$\mathrm{O}$ adequado funcionamento de qualquer modelo de democracia apresenta, enquanto um de seus requisitos essenciais, o acesso a determinadas capacidades por parte dos diversos agentes envolvidos nesse processo.

Partindo-se, portanto, da noção de capacidade ${ }^{3}$ como um conjunto de oportunidades (ou condições externas) para a realização de escolhas, poder-se-ia analisá-la, do ponto de vista da democracia, sob dois aspectos. Numa primeira vertente, as oportunidades/condições para a realização de escolhas estariam associadas à existência, ao funcionamento e ao acesso dos diferentes atores a instâncias, espaços e mecanismos de deliberação e decisão. Tal perspectiva remete, por um lado, aos modelos de representação, participação e deliberação, bem como, por outro lado, às regras estabelecidas para o exercício do jogo democrático. Numa segunda vertente, as oportunidades/condições para a realização de escolhas estariam ligadas ao domínio - ou, se necessário, à possibilidade de obtenção -, pelos diversos atores, dos recursos essenciais ao desempenho de suas funções no contexto da democracia. Um desses recursos - senão o principal deles - diz respeito à informação e ao conhecimento ${ }^{4}$, cuja importância tem se evidenciado, de forma crescente, tanto na atuação dos agentes públicos quanto na relação entre estes e a sociedade.

Decorre logicamente daí que a realização de escolhas, nas diversas instâncias e situações da arena pública, será tanto mais adequada e efetiva, quanto maior o grau de informação e conhecimento possuído ou disponível para os agentes responsáveis por essas escolhas. Seria de se esperar, portanto, num plano ideal, que os diversos agentes públicos e sociais tivessem pleno controle e/ou acesso a todas as informações e conhecimentos necessários à sua melhor atuação nesse processo. Mas a realidade, ao contrário, é marcada por uma acentuada assimetria informacional entre esses agentes, ou seja, por uma “[...] desigualdade de condições para acesso [...] a informações relativas a questões que, por sua importância, influenciam diretamente no processo decisório de formulação de políticas públicas" (Prata, 2007).

Ribeiro (2007) se incumbiu de trazer essa discussão para o âmbito do Poder Legislativo, inicialmente no sentido de reconhecer e defender o potencial do parlamento como espaço

\footnotetext{
${ }^{3}$ Segundo Anastasia e Inácio (2006), com base em conceito formulado por Amartya Sem, “[...] a noção de capacidade envolve a idéia de oportunidades, ou seja, condições externas para realizar escolhas [ ]. Ser capaz envolve, ainda, a possibilidade de fazer escolhas, ou seja, a idéia de capacidade remete não só às realizações mas também à liberdade substantiva de proceder escolhas".

${ }^{4}$ A despeito da consciência quanto às diferenças conceituais entre informação e conhecimento, optou-se aqui por não trabalhar essa distinção, dada, por um lado, a grande proximidade e o uso, muitas vezes, indiscriminado de ambos os termos, bem como, por outro, a inviabilidade e a não pertinência de tal distinção em relação aos limites e objetivos deste artigo.
} 
próprio "[...] para a ampliação do acesso à informação e ao conhecimento e para constituição de um ambiente favorável ao aprendizado coletivo". Além disso, esse autor não apenas aponta outras formas de assimetria informacional existentes especificamente no contexto das relações internas e externas do Poder Legislativo, como alerta para o papel central desempenhado pelo próprio parlamento nesse cenário. É ainda esse autor que, na esteira desse raciocínio, irá repensar as funções do Poder Legislativo no contexto da sociedade da informação e do conhecimento, incluindo, ao lado das tradicionais funções legislativa e fiscalizadora, também outras funções complementares àquelas, como a informadora e a educativa. Segundo ele, essas funções complementares decorrem do processo adotado pelo Legislativo para realizar suas deliberações e produzir suas decisões, do qual emerge - nos termos preconizados pela teoria da democracia deliberativa - a própria legitimidade tanto do Poder quanto da sua produção.

Nesse ponto, mais que concordar com o referido autor, propõe-se aqui uma ampliação desse entendimento, no sentido de se tentar reconhecer que todos os poderes e órgãos públicos e não apenas o Legislativo -, ainda que nos limites das respectivas esferas de atuação, detêm, a par de suas funções precípuas, outras funções complementares, especialmente voltadas para a informação e a educação. Não se pretende, com isso, deixar de considerar a prevalência que tais funções complementares têm no contexto do Poder Legislativo, seja em virtude do pluralismo informacional e cognitivo inerente à sua atuação, seja em decorrência da condição e das responsabilidades deste Poder como principal mediador das relações entre cidadãos e Estado. Mas também não se pode deixar de reconhecer, por outro lado, que, ainda que em menor grau, mesmo os demais poderes e órgãos públicos, no desempenho de suas funções precípuas, se colocam tanto como receptores das informações necessárias ao exercício de suas atribuições, quanto como fontes difusoras das informações decorrentes desse exercício.

A constatação da existência de uma função informadora por parte dos poderes e órgãos públicos, não apenas atende, assim, às exigências dos princípios constitucionais da publicidade e do direito à informação, como também se coaduna com as iniciativas e esforços que têm sido promovidos por diversas dessas instituições no sentido de dar transparência à sua atuação e à de seus agentes. Exemplo disso é a crescente preocupação dos poderes e órgãos públicos no sentido da utilização dos meios e tecnologias de informação e comunicação - especialmente, a internet e, em menor medida, a TV e o rádio - como canais para a disponibilização de informações e veiculação de notícias sobre o trabalho por eles desenvolvido.

A despeito, no entanto, desses avanços no processo de transparência pública, faz-se necessário avaliar em que medida o acesso, ainda que ampliado, à informação e ao conhecimento tem sido suficiente, por si só, para prover as capacidades requeridas para o adequado desempenho dos atores na arena democrática. É de se perguntar, nesse sentido, 
porque, mesmo com todo o aparato de comunicação e de disponibilização de informações hoje mantido, de forma ampla e igualitária, pelos diversos poderes e órgãos públicos, ainda não se conseguiu eliminar ou, pelo menos, minimizar os efeitos da desigualdade de acesso às informações, base das relações de dominação verificadas no âmbito da sociedade. Analisandose essa questão sob a perspectiva do Estado, cabe questionar, da mesma forma, porque, com todas as alternativas e facilidades de acesso a informações e conhecimentos existentes nos dias atuais, ainda não se conseguiu traduzir isso num melhor desempenho das funções e atribuições dos poderes e agentes públicos perante a sociedade. Ainda, sob o ângulo das relações entre sociedade e Estado, faz-se necessário repensar também porque, com todo o movimento rumo à transparência pública e com as diversas possibilidades de participação e deliberação proporcionadas pelas mídias eletrônicas, hoje largamente utilizadas pelos poderes públicos, ainda não se conseguiu reverter ou, pelo menos, estancar o crescente processo de despolitização dos cidadãos comuns.

Tem-se plena consciência, por óbvio, que o quadro acima delineado, não apenas pode ser analisado sob diversos aspectos, como resulta de inúmeros fatores e variáveis, tanto estruturais quanto culturais, cuja abrangência e profundidade não seria possível contemplar nos limites do presente texto. O que se pretende aqui demonstrar, no entanto, é que há, no plano das relações democráticas, uma clara distinção entre a disponibilização de informações e o seu efetivo acesso e uso por parte daqueles a quem elas se destinam ou que delas têm necessidade. Nesse sentido, segundo Prata (2007),

o desenvolvimento e o estabelecimento de uma política de divulgação constante de informações por parte das instituições do Estado, ainda que atenda a preceitos legais e possa ser considerada uma atitude louvável do poder público, pouco contribuirá para o aumento dos níveis de 'accountability' da ordem democrática se a sociedade não for formada por cidadãos capazes de compreender e efetivamente utilizar essas informações para controlar seus governantes e representantes, no sentido de fazer com que as ações destes se aproximem das preferências e expectativas daqueles (Prata, 2007).

Esse autor avança ainda na discussão do tema, introduzindo a ideia de que a efetiva utilização da informação e do conhecimento no âmbito da vida política depende - da mesma forma que a democracia - de certas capacidades por parte dos atores envolvidos nesse processo. Para tanto, Prata (2007) traz à baila o conceito de "competência informacional", definido como “[...] a habilidade em reconhecer quando existe uma necessidade de informação e a capacidade de identificar, recuperar, avaliar e usar eficazmente essa informação para a resolução de um problema ou para a tomada de uma decisão".

Uma análise mais detida do conceito acima permite associar a noção de competência informacional a dois sentidos distintos, embora complementares: um, de ordem subjetiva, referente ao reconhecimento preliminar, pelo próprio cidadão, da existência de uma necessidade de informação; e outro, de ordem objetiva, relacionado com as condições externas de acesso e 
de uso das informações necessárias ao atendimento de uma demanda pré-identificada. No que se refere a esse último aspecto, cabe destacar, como um dos elementos fundamentais da competência informacional, a capacidade do cidadão em compreender e utilizar tais informações.

Tem-se, assim, uma preocupação essencial no sentido de que os agentes democráticos consigam, indo além do mero acesso à informação, atingir plenamente o seu conteúdo e, ainda mais que isso, que sejam capazes, a partir daí, de incorporar tal informação ao seu próprio arsenal de conhecimentos, a fim de utilizá-los de forma eficaz e articulada ${ }^{5}$. Essa preocupação ganha relevo especial quando se pretende que esses agentes atuem num contexto de democracia deliberativa, o qual pressupõe capacidade de reflexão e argumentação, não apenas sobre as razões e pontos de vista do próprio indivíduo, mas também, e principalmente, sobre as dos demais interlocutores na arena pública.

Decorre daí, primeiramente, a percepção de que é possível a formação e/ou o desenvolvimento das competências necessárias ao efetivo acesso e uso da informação de natureza política, bem como, por consequência, das capacidades requeridas para a melhor atuação dos cidadãos no exercício da democracia. Decorre também, em segundo lugar, a possibilidade de ampliação desse raciocínio no sentido de se entender esse esforço de formação/desenvolvimento de competências e capacidades como uma necessidade não apenas por parte dos cidadãos, mas de todos os agentes públicos e sociais envolvidos com o exercício da democracia. Decorre, finalmente, o reconhecimento da educação como instrumento hábil, adequado e decisivo para a formação/desenvolvimento de tais competências e capacidades.

O que aqui se defende, então, é que informação e educação, embora atuando sob perspectivas, princípios e contextos próprios, são processos que se articulam e complementam no sentido da construção das bases para o adequado funcionamento da democracia. A educação estaria, assim, no processo de construção das condições para a participação democrática, localizada em um ponto anterior à informação, servindo como base e suporte para a efetiva compreensão, assimilação e uso desta. Segundo essa concepção, a educação exerceria, no contexto democrático, o papel de uma "meta-informação", ou seja, de um conjunto de informações necessário ao acesso e ao melhor aproveitamento da informação propriamente dita. Importante perceber ainda que a educação apresenta, da mesma maneira que a informação, uma relação intrínseca e circular com o modelo e com a dinâmica da democracia deliberativa, constituindo, simultaneamente, insumo e produto dos processos de deliberação pública ${ }^{6}$.

\footnotetext{
5 Segundo Prata (2007), "o desenvolvimento de competências para que as pessoas tenham capacidade de buscar, recuperar e filtrar as informações (ou de exigir o acesso a elas), promovendo sua apropriação crítica, é um dos fatores primordiais para que possam utilizá-las como elemento de emancipação individual”.

6 Segundo Manin (2007), "a deliberação política e a argumentação [ ] requerem também um certo grau de instrução e cultura por parte do público, mas constituem elas próprias um processo de educação e treinamento. Elas ampliam os pontos de vista dos cidadãos para além da perspectiva de seus casos privados. Elas propagam esclarecimento".
} 
Cabe considerar, finalmente, que as imensas possibilidades que se abrem para a educação no sentido da ampliação e fortalecimento da prática democrática podem estar relacionadas, em certa medida, a uma percepção positiva - ou, pelo menos, não tão carregada de "pré-conceitos" - que os indivíduos têm desta. A educação, com isso, se coloca - ou é vista num patamar diferenciado em relação aos processos de informação e comunicação mantidos pelas instituições públicas, os quais, apesar de toda a preocupação com o respeito aos princípios da ética e da transparência, ainda estão mais sujeitos a uma percepção de manipulação ou direcionamento em função dos interesses em disputa. Contribui certamente para isso a manutenção - ou a percepção - de um certo distanciamento entre a cena política propriamente dita e os processos educativos conducentes à formação das competências e capacidades requeridas dos agentes para nela atuarem. Com isso é que, na visão de Castro, a educação, "sem os conflitos e as tensões das instâncias de tomada de decisão ou de deliberação, como em um jogo amistoso, pode preparar políticos, técnicos e sociedade para o jogo democrático e qualificar a participação política para a construção de uma democracia cada vez mais plena" (Castro apud Cosson, p. 188, 2008).

\section{Educação e Democracia: Limites e Responsabilidades}

Avançando no sentido do estabelecimento dos limites e das responsabilidades por essa educação para o exercício democrático, defende-se aqui, inicialmente, que cada poder e órgão público, enquanto parte do aparato estatal criado para o atendimento das necessidades e expectativas da sociedade, tem sua cota de contribuição para esse esforço educativo necessário à manutenção e ao adequado funcionamento da democracia, canal privilegiado de ligação e interação entre cidadãos e Estado.

Uma educação voltada para a prática democrática seria, assim, a resultante da soma das ações desses poderes e órgãos, dentro das respectivas áreas de competência e atuação, no sentido da qualificação, não apenas dos próprios agentes públicos, mas também dos diversos segmentos da sociedade. Essa educação para a democracia poderia ser entendida, partindo-se de conceito formulado por Cosson (2008), como o conjunto de ações e programas desenvolvidos pelos poderes e órgãos públicos no sentido da apropriação, tanto por parte de seus próprios agentes quanto da sociedade, de práticas, conhecimentos e valores para a manutenção e aprimoramento da democracia.

Tal conceituação baseia-se nos seguintes pressupostos: de que os diferentes poderes e órgãos públicos, nas três esferas de governo, são co-responsáveis, respeitada a abrangência e o campo temático de atuação de cada um, pelo processo de formação das competências e capacidades necessárias ao pleno exercício e funcionamento da democracia; de que essa 
formação deve atingir, tanto quanto possível, não apenas os próprios componentes de cada poder/órgão e os demais agentes da esfera pública (estejam estes na condição de membros, servidores ou auxiliares), como também, e principalmente, os diferentes segmentos da sociedade; de que essas ações e programas devem ser planejados, concebidos e executados na medida das necessidades, capacidades e características de cada agente público ou social, em face da sua posição e atuação no espectro da vida política e democrática; de que essas ações e programas devem buscar, mais que um simples aprendizado, a verdadeira apropriação de práticas, conhecimentos e valores essenciais à vida política e à democracia; e, finalmente, de que a educação para a democracia precisa ser um processo contínuo e concatenado, que tenha como finalidade, a longo prazo, uma verdadeira mudança de culturas, posturas e mentalidades.

Entendida, portanto, a educação para a democracia como um esforço a cargo dos poderes e órgãos públicos, há que se ter cuidado para que esta não se transforme em mais um mecanismo de manipulação e de manutenção da assimetria informacional entre instituições e atores envolvidos no processo político-democrático. É fundamental, para tanto, que as ações e programas desenvolvidos no âmbito da educação para a democracia sejam orientados por uma prática pedagógica que privilegie e dê sustentação à formação de uma consciência crítica e emancipadora dos indivíduos, estejam eles na condição de agentes públicos ou de integrantes da sociedade.

Tal entendimento nos permite também retomar o argumento de Ribeiro (2007), ampliado nos termos do presente estudo, no sentido de reconhecer que todos os órgãos e poderes públicos - e não apenas o Legislativo -, ainda que nos limites das respectivas esferas de atuação, detêm, a par de suas funções precípuas, também uma função educativa. Importante ressaltar que a ideia de educação - como, de resto, de informação - como "função" vai muito além de uma mera preocupação, ou mesmo responsabilidade, por parte das instâncias públicas, assumindo, nessa perspectiva, uma condição de obrigatoriedade e de permanência.

Não é sem razão, portanto, a previsão constitucional de existência de "escolas de governo" no âmbito da União, dos Estados e do Distrito Federal ${ }^{7}$. Embora a redação do texto constitucional traduza, em princípio, um direcionamento dessas "escolas" para a capacitação de servidores públicos, isso já não deixa de ser, por si só, um reconhecimento do papel e do espaço representado pela educação no contexto da esfera pública. Tem-se, hoje, ademais, uma compreensão bastante mais ampliada acerca do alcance desse dispositivo, seja quanto à abrangência da expressão "escola de governo", seja quanto à amplitude das atividades e programas desenvolvidos por esses órgãos. Assim é que, apesar das diferentes denominações e caracterizações adotadas, podem ser considerados como "escolas de governo", em sentido lato,

\footnotetext{
7 “Art. 39, § $2^{\circ}$ - A União, os Estados e o Distrito Federal manterão escolas de governo para a formação e o aperfeiçoamento dos servidores públicos [...]”. (BRASIL, 1988).
} 
todos os órgãos e setores mantidos ou vinculados às diversas instâncias do Poder Público, nos níveis federal, estadual e municipal, que atuem, direta ou indiretamente, em ações de educação. Depreende-se daí, com base nessa conceituação ampla, que tais ações de educação não precisam estar restritas - embora, em grande parte dos casos, ainda o estejam - à formação e ao aprimoramento dos servidores (ou mesmo dos membros) dessas instituições. Por esse entendimento, permite-se (ou mais que isso, espera-se) que cada uma dessas "escolas" - ou, nos casos em que estas não existam, a própria instituição - seja um pólo difusor, junto aos demais agentes da esfera pública, bem como junto à sociedade, dos conhecimentos próprios ao âmbito e/ou ao campo temático de atuação das respectivas instituições. Ter-se-ia, com isso, uma grande rede de educação para a democracia, em que - por meio de uma atuação articulada e baseada numa espécie de "divisão do trabalho" entre as instituições -, caberia aos órgãos públicos não apenas se alimentarem, uns aos outros, das informações e conhecimentos sob suas respectivas competências, como também a todos eles, juntos, se encarregarem de fazê-lo em relação à sociedade.

Cabe mencionar, nesse sentido, algumas iniciativas concretas de organização e trabalho em rede, por parte das instituições públicas, como também a forte tendência contemporânea no sentido desse movimento de parceria e articulação de ações, com todas as possibilidades que isso acarreta. A par, assim, de diversas redes e associações "setoriais" - como, por exemplo, entre escolas ligadas aos Legislativos, à magistratura, dentre outras -, cujo processo de articulação obedece a uma dinâmica mais natural, diante da similaridade de atuação e de interesses, merecem menção duas iniciativas de integração ampliada, ora em curso, quais sejam: no plano nacional, a Rede Nacional de Escolas de Governo ${ }^{8}$, coordenada pela Escola Nacional de Administração Pública (ENAP) e composta por órgãos de educação de todo o País, ligados aos diversos poderes e esferas de governo, na administração direta, autárquica ou fundacional; e, no plano estadual, a Rede de Escolas de Formação de Agentes Públicos de Minas Gerais (REAP/MG), que congrega "escolas" de diversos órgãos públicos com sede no Estado, vinculadas aos governos federal, estadual e municipal.

Configurada, assim, a ideia de que a responsabilidade pela educação para a democracia deve ser, ao mesmo tempo, dividida e compartilhada entre os diversos poderes e órgãos públicos, especialmente por meio das respectivas "escolas de governo", resta tentar compreender o espaço e as possibilidades da educação legislativa e, por consequência, do Poder Legislativo nesse contexto.

\section{Educação Legislativa: Função do Parlamento e Missão das Escolas do Legislativo}

\footnotetext{
${ }^{8}$ Mais informações no endereço http://www.enap.gov.br
} 
Embora não seja possível uma delimitação exata do papel do parlamento e, por consequência, de seus esforços educativos específicos, em relação ao contexto mais amplo da educação para a democracia, faz-se necessário constatar que o Poder Legislativo, pela sua posição central no processo de organização e funcionamento da vida democrática, tem um papel especial e diferenciado nesse cenário. O Poder Legislativo é, sem sombra de dúvida, o ponto de convergência e de convivência dos modelos e instrumentos de representação, participação e deliberação política, essenciais para o adequado relacionamento entre Estado e sociedade. É, ainda, o poder responsável, de forma precípua, por atribuições que constituem a base e a própria tradução dos princípios democráticos, quais sejam: a elaboração das normas encarregadas de organizar a vida em sociedade, com base nas demandas e expectativas desta; a fiscalização da atuação dos demais entes estatais, especialmente do Executivo, de forma a garantir o equílibrio entre os poderes e a accountability; e, numa ênfase mais recente, a participação ativa no planejamento, acompanhamento e avaliação das políticas públicas de responsabilidade do Estado. O exercício de tais (e tantas) atribuições requer, por evidente, competências e capacidades específicas, por parte de todos os atores envolvidos, tanto públicos quanto sociais, ensejando a necessidade de um processo educativo capaz de atender às demandas e peculiaridades do Poder Legislativo.

Mas essa centralidade do Poder Legislativo no contexto de organização e funcionamento da democracia o caracteriza também como o mais aberto e permeável entre os órgãos que compõem a estrutura do Estado, o que, se por um lado, é positivo em termos de abertura à participação e à pluralidade de interesses, por outro, gera o efeito "perverso" de torná-lo suscetível a práticas nem sempre condizentes com o espírito da verdadeira representação dos anseios sociais. Decorre daí, dentre outros fatores, o enfraquecimento da sua legitimidade e representatividade, bem como, por consequência, o crescente esvaziamento e/ou usurpação de suas funções precípuas por outros entes do aparato estatal. Desponta, também nesse sentido, a importância, para o Poder Legislativo, de um processo educativo que propicie, tanto aos agentes públicos quanto à sociedade, a exata compreensão desse cenário e que contribua, com isso, para o resgate e a (re)valorização da representação democrática.

Necessário retomar, nesse ponto, a percepção de que ao Legislativo, assim como a cada um dos demais poderes e órgãos públicos, compete, mais que uma responsabilidade, uma função educativa, a ser exercida de forma obrigatória e permanente. No caso do parlamento, em especial, essa função educativa, ao mesmo tempo em que dá suporte para o efetivo exercício das demais atribuições tradicionalmente reconhecidas como precípuas do Legislativo, com estas se entrelaça e articula, num processo contínuo de retroalimentação. Assim é que - como preconizado pelos princípios da democracia deliberativa, que tem no parlamento o seu locus privilegiado -, a educação constitui, simultaneamente, insumo e produto, condição e resultado da atuação e da interação dos diferentes atores, tanto públicos quanto sociais, no exercício das 
funções do Legislativo. Não bastasse isso para justificar a existência e a importância de uma função educativa do parlamento, configura-se esta hoje, em última análise, como fator de sobrevivência para o Legislativo, especialmente em face do atual cenário de crise da representação política, bem como de enfraquecimento e perda de legitimidade deste Poder, como acima mencionado.

É, portanto, o processo educativo que, embora compondo o panorama maior da educação para a democracia, visa atender as demandas e peculiaridades próprias do Poder Legislativo e, mais que isso, se caracteriza como função permanente deste, que aqui se está propondo denominar como "educação legislativa". A educação legislativa seria, assim, uma ação consciente e organizada do parlamento no sentido de capacitar e qualificar a atuação dos agentes envolvidos no processo de representação e participação democrática - tanto no âmbito das próprias casas legislativas, quanto das demais instituições estatais e, em especial, da sociedade -, sob a perspectiva específica das questões inerentes às funções e à atuação do Poder Legislativo.

Retomando-se entendimento anterior acerca do papel da educação na formação de competências para o exercício democrático sob os aspectos objetivo e subjetivo, pode-se agora aplicá-lo especificamente à educação legislativa, no sentido de perceber o alcance das suas possibilidades e responsabilidades. No aspecto objetivo, portanto, a educação legislativa estaria relacionada à instrumentalização dos atores públicos e sociais para o exercício, de forma direta ou indireta, das funções e atribuições do parlamento, especialmente no âmbito da elaboração legislativa, da fiscalização, do acompanhamento das políticas públicas e da representação político-parlamentar. No aspecto subjetivo, por sua vez, o foco da educação legislativa estaria voltado para a sensibilização, conscientização, motivação e mobilização, tanto dos agentes públicos quanto dos cidadãos, não apenas para um adequado conhecimento e reconhecimento do Poder Legislativo no contexto democrático, como para a percepção, valorização e utilização deste como canal por excelência da representação e da participação política. Necessário lembrar, embora seja (ou pareça) óbvio, que essas duas dimensões da educação legislativa não existem de forma estanque, mas que, ao contrário, se interligam, se sobrepõem e se complementam o tempo todo.

O reconhecimento da educação legislativa, enquanto tradução e materialização da função educativa do parlamento, tem levado, no âmbito dessas casas, a um processo de crescente valorização e consolidação das "escolas do legislativo" como os espaços próprios para o efetivo exercício dessa missão pedagógica. É a essas escolas, portanto, que tem sido confiada, cada vez mais, a responsabilidade, tanto pela formação das competências e capacidades instrumentais necessárias ao desempenho das atribuições e funções do Legislativo, quanto pela sensibilização e conscientização dos atores públicos e sociais em relação ao papel e à importância da representação e da participação política, bem como em relação à 
imprescindibilidade do parlamento no contexto da vida democrática. Esses órgãos têm se constituído, assim, nas "escolas de governo" das casas legislativas, mas com uma atuação pautada segundo a percepção ampliada defendida no bojo deste trabalho, qual seja a de espaços destinados não apenas à formação e ao aprimoramento de servidores, mas também, e especialmente, à difusão, junto aos demais agentes da esfera pública, bem como junto à sociedade, dos conhecimentos e questões próprios do parlamento.

Importante registrar que, a despeito de só em 1998, por meio da Emenda ${ }^{\circ} 19-$ anteriormente mencionada -, ter-se instituído a previsão constitucional de existência de "escolas de governo" no âmbito da União, dos Estados e do Distrito Federal, as "escolas do legislativo" existem desde 1992, a partir de uma iniciativa pioneira da Assembleia Legislativa do Estado de Minas Gerais ${ }^{9}$. A partir do exemplo e do modelo de Minas Gerais, várias outras casas legislativas do País, tanto em nível federal quanto estadual, passaram, especialmente nos últimos dez anos, a instituir, a ampliar e a consolidar as próprias "escolas do legislativo". Esse movimento ganhou reforço significativo com a criação, em 2003, da Associação Brasileira das Escolas do Legislativo - ABEL $^{10}$, que, além de congregar também as escolas dos Tribunais de Contas da União e dos estados, contribuiu para a disseminação dessa iniciativa junto a todos os parlamentos estaduais e, mais recentemente, junto às câmaras municipais, principalmente aquelas das capitais ou de municípios de médio e grande porte espalhados pelo País. Vale mencionar, à guisa de informação, que, apenas em Minas Gerais, como resultado de um esforço próprio da Assembleia Legislativa estadual, já existem escolas, em funcionamento ou em processo de criação, nas câmaras das cidades-pólo de praticamente todas as dez macrorregiões em que se divide administrativamente o Estado. Necessário lembrar também o importante papel desempenhado pelo Programa Interlegis ${ }^{11,}$ mantido pelo Senado Federal, no sentido do fomento à estruturação e ao funcionamento de uma comunidade entre as casas legislativas e os parlamentares de todos os níveis de governo, com ênfase, mais recentemente, em ações e projetos de educação, informação e comunicação, desenvolvidos em grande sintonia com as escolas do legislativo.

Acredita-se que essa atuação em rede, na perspectiva específica das casas e escolas do legislativo, com todas as oportunidades e possibilidades de integração, articulação e compartilhamento de experiências daí decorrentes, será fundamental para uma ampliação e consolidação cada vez maior dos esforços rumo a uma educação legislativa que contribua, de forma efetiva, para o fortalecimento da democracia.

\footnotetext{
${ }^{9}$ Vide nesse sentido: ASSIS, Luiz Fernandes de. Educando para a cidadania: a experiência da Escola do Legislativo. Educação \& Sociedade, Campinas, v. 18, n. 59, p. 369-387, ago. 1997.

${ }^{10}$ Mais informações no endereço http://www.portalabel.org.br .

${ }^{11}$ Mais informações no endereço http://www.interlegis.gov.br .
} 


\section{Conclusão}

O adequado exercício da democracia depende de determinadas capacidades e competências por parte de todos os agentes, tanto públicos quanto sociais, envolvidos nesse processo, e a educação, enquanto base para a obtenção e utilização de informações, é o instrumento hábil para o atendimento a tais requisitos.

Dentro de um contexto mais amplo de educação para a democracia, cuja responsabilidade deve ser dividida e compartilhada entre os diversos poderes e órgãos públicos, cabe ao parlamento a função de promover a educação legislativa, voltada para a disseminação de conhecimentos e reflexões decorrentes da atuação e dos interesses específicos desse Poder.

Compete às escolas do legislativo, enquanto espaços para essa educação legislativa, perceber a diversidade e a potencialidade de seus públicos e linhas de atuação, bem como identificar e compreender as características, peculiaridades e necessidades de cada um, com vistas à formulação de um projeto pedagógico adequado e eficaz.

\section{Referências}

ANASTASIA, Fátima; INÁCIO, Magna. Democracia, Poder Legislativo, interesses e capacidades. Belo Horizonte, 2006. Não publicado.

ASSIS, Luiz Fernandes de. Educando para a cidadania: a experiência da Escola do Legislativo. Educação \& Sociedade, Campinas, v. 18, n. 59, p. 369-387, ago. 1997.

BRASIL. Constituição (1988). Constituição da República Federativa do Brasil. Brasília, 1988.

COSSON, Rildo. Escolas do Legislativo, escolas de democracia. Brasília: Câmara dos Deputados, Edições Câmara, 2008. (Série Colóquios de Excelência, 1).

PRATA, Nilson Vidal. Informação e democracia deliberativa: a dimensão informacional do processo de elaboração participativa das leis. In: CONGRESSO INTERNACIONAL DE LEGÍSTICA, 2007, Belo Horizonte. [Comunicações...]. Disponível em: <www.almg.gov.br/eventos/ legistica/pdf >. Acesso em: 1 jul. 2008.

MANIN, Bernard. Legitimidade e deliberação política. In: WERLE, Denílson Luis, MELO, Rúrion Soares (Org.). Democracia deliberativa. São Paulo: Singular, 2007.

RIBEIRO, Guilherme Wagner. Poder Legislativo: entre a assimetria informacional e o pluralismo cognitivo. Legislação, Lisboa, n. 45, p. 5-23, mar. 2007.

WERLE, Denílson Luis, MELO, Rúrion Soares (Org.). Democracia deliberativa. São Paulo: Singular, 2007. 